\title{
FORMULATION AND IN-VITRO EVALUATION OF HOLLOW MICROSPHERES OF GLIPIZIDE
}

\author{
Available online at www.ijdra.com \\ RESEARCH ARTICLE \\ ${ }^{1}$ Kumar Arun ${ }^{*},{ }^{2}$ Midda Anil, ${ }^{3}$ Jhanjharia Mahesh \\ ${ }^{1}$ Jaipur School of Pharmacy, Maharaj Vinayak Global University, Jaipur, Rajasthan, India \\ ${ }^{2}$ OPJS University, Churu, Rajasthan, India \\ ${ }^{3}$ Saroj College of Pharmacy, Lucknow, U.P., India \\ *Corresponding Author's E-mail: arunph2007simple@gmail.com
}

DOI: https://doi.org/10.22270/ijdra.v5i4.211

\begin{abstract}
Present work involves attempts to improve floating time of glipizide by formulation of hollow microspheres incorporating Glyceryl Monostearate and acryflow. The floating microspheres were evaluated for percentage yield, drug loading, In-vitro buoyancy behavior as well as in-vitro drug release. The micrometric properties were found to be good and scanning electron microscopy shows that the microspheres were spherical with smooth surface and a hallow cavity inside microspheres. The practical yield was found to be in the range of 83.88-90.98\% and with a particle size range of $320-480 \mu \mathrm{m}$. The percent entrapment is about $76 \%$ to $91 \%$ which decreased with increase in HPMC concentration in the formulations. The microspheres with high concentrations of Acrycoat S100 showed higher buoyancy. The in-vitro release was slow and extended to more than 12 hours which increased with significant increase in HPMC concentration but decreased in buoyancy character. Release obeys zero order kinetics and the drug release was diffusion controlled. Hence it can be concluded that the floating microsphere of Glipizide may prolong drug release thereby improving bioavailability and enhance opportunity of absorption in stomach.
\end{abstract}

Keywords: Hollow microspheres, floating time, glipizide, HPMC.

\section{INTRODUCTION}

Glipizide is a second-generation oral sulfonylurea hypoglycemic agent used in lowering the blood sugar levels in patients with non-insulin dependent diabetes mellitus. Gastrointestinal absorption is uniform, rapid and essentially complete with peak plasma concentration occurring 1 to $3 \mathrm{hrs}$ after a single dose. It is extensively bound to plasma proteins and a half-life of approximately 2 to $4 \mathrm{hrs}$. In order to maintain therapeutic plasma concentration, the drug must be administered frequently by oral route in divided doses which leads to fluctuations in plasma drug levels.(1-3) To overcome inherent drawbacks associated with conventional dosage forms of Glipizide, an attempt is being made to develop an alternative drug delivery system in the form of floating microspheres

Glyceryl Monostearate has been used in preparation of hollow microspheres by emulsification solvent diffusion technique. It works as wall membrane reinforcing agent.

Acryflow is hydrogenated castor oil which has been used in the novel pharmaceutical composition containing an active ingredient which is retained in the stomach or upper part of gastrointestinal tract for controlled delivery of medicament. It has been shown that the nature of the drug formulation can influence the dissolution process. Solubility of glipizide increases by addition of HPMC which act as release modifying ingredient of the formulation. Present work involves attempts to improve floating time of glipizide by formulation of hollow microspheres incorporating Glyceryl Monostearate and acryflow. Further studies were done for the improvement of dissolution of the Glipizide by addition of HPMC polymers.

\section{EXPERIMENTAL}

Material and Methods 
Preparation and Optimization of Acrycoat S100 microspheres of Glipizide $(4,5)$

Glipizide, Acrycoat S100, Acrycoat L100, Hydroxy propyl methyl cellulose, Glyceryl Monostearate and acryflow in quantities shown in Table 1 and 2 were dissolved in a mixture of Ethanol, IPA and Dichloromethane (4:6:5). This mixture was poured in a $500 \mathrm{ml}$ water containing $1 \%$ PVA maintained at a temperature of $30^{\circ} \mathrm{C}$ with stirring at $250 \mathrm{rpm}$. Stirring was continued for $1 \mathrm{hr}$. to allow the volatile solvent to evaporate. The microspheres formed were filtered, washed with D.M.water and dried overnight at $40^{\circ} \mathrm{C}$ in oven.

Table 1: Composition of microspheres of Batch 1 to $\mathrm{B3}$

\begin{tabular}{|l|c|c|c|}
\hline Ingredients & B1 & B2 & B3 \\
\hline Glipizide & $500 \mathrm{mg}$ & $500 \mathrm{mg}$ & $500 \mathrm{mg}$ \\
\hline $\begin{array}{l}\text { Acrycoat } \\
\text { S100 }\end{array}$ & $1000 \mathrm{mg}$ & $1000 \mathrm{mg}$ & $1000 \mathrm{mg}$ \\
\hline Acryflow & - & $500 \mathrm{mg}$ & - \\
\hline GMS & - & - & $200 \mathrm{mg}$ \\
\hline
\end{tabular}

Table 2: Composition of microspheres of Batch B4 to B7

\begin{tabular}{|c|c|c|c|c|}
\hline Ingredients & B4 & B5 & B6 & B7 \\
\hline Glipizide & $\begin{array}{c}500 \\
\mathrm{mg}\end{array}$ & $\begin{array}{l}500 \\
\mathrm{mg}\end{array}$ & $\begin{array}{l}500 \\
\mathrm{mg}\end{array}$ & $\begin{array}{l}500 \\
\mathrm{mg}\end{array}$ \\
\hline $\begin{array}{l}\text { Acrycoat } \\
\text { S100 }\end{array}$ & $\begin{array}{c}800 \\
\mathrm{mg}\end{array}$ & $\begin{array}{c}800 \\
\mathrm{mg}\end{array}$ & $\begin{array}{c}800 \\
\mathrm{mg}\end{array}$ & $\begin{array}{l}800 \\
\mathrm{mg}\end{array}$ \\
\hline $\begin{array}{l}\text { Acrycoat } \\
\text { L100 }\end{array}$ & $\begin{array}{l}150 \\
\mathrm{mg}\end{array}$ & $\begin{array}{l}250 \\
\mathrm{mg}\end{array}$ & - & - \\
\hline GMS & - & - & $\begin{array}{l}300 \\
\mathrm{mg}\end{array}$ & - \\
\hline HPMC & - & - & $\begin{array}{l}100 \\
\mathrm{mg}\end{array}$ & $\begin{array}{l}100 \\
\mathrm{mg}\end{array}$ \\
\hline Acryflow & $\begin{array}{c}300 \\
\mathrm{mg}\end{array}$ & $\begin{array}{l}300 \\
\mathrm{mg}\end{array}$ & - & $\begin{array}{l}350 \\
\mathrm{mg} \\
\end{array}$ \\
\hline
\end{tabular}

\section{Percentage Yield $(6,7)$ :}

The prepared microspheres were collected and weighed from different formulations. The measured weight was divided by the total amount of all nonvolatile components which were used for the preparation of the microspheres.
$\%$ Yield

$$
=\frac{\text { Actual weight of product }}{\text { Total weight of drug and polymer }} \times 100
$$

Particle size analysis: (8)

The sizes of floating microspheres were measured by using an optical microscope, and the mean particle size was calculated by measuring nearly 200 particles with the help of a calculated ocular micrometer.

\section{Buoyancy behavior of Floating microsphere (9):}

The percentage of microspheres was calculated by the following equation:

$$
\begin{aligned}
& \% \text { Floating } \\
& =\frac{\text { Weight of floating microspheres }}{\text { Initial weight of microspheres }} \times 100
\end{aligned}
$$

\section{Encapsulation Efficiency: $(10,11)$}

Drug Loading was calculated as:

$$
\begin{aligned}
& \text { DL }(\% \quad \text { Actual Drug Content } \\
& =\frac{\text { Weight of Powdered Microspheres }}{\text { Pow }} \times 100
\end{aligned}
$$

\section{In vitro drug release study (5)}

Drug release study from the hollow microspheres is complicated because the hollow microspheres float and hence adhere to the inside surfaces of the dissolution basket while the dissolution experiments are in progress, which leads to the nonparticipation of the hollow microspheres or their surface in the release study. Hollow microspheres have the propensity to exhibit a buoyancy effect in vivo, but the development of a dissolution method as a quality control tool with the simulated buoyant condition is difficult.

The drug release rate from floating microspheres was determined using USP XXIII basket type dissolution apparatus. A weighed amount of floating microspheres equivalent to $10 \mathrm{mg}$ glipizide was taken for dissolution study. The microspheres were placed in a non-reacting mesh nylon bolting cloth that had a smaller mesh size $(200$ \#) than the microspheres. The mesh was tied with a nylon thread to avoid the escape of any microspheres, and glass marble 
was used in the mesh to help induce any possible sinking of the microspheres in the dissolution medium. Simulated gastric fluid (SGF, pH 2.0) (500 ml) containing Tween 20 $(0.02 \mathrm{w} / \mathrm{v} \%)$ was used as the dissolution medium and maintained at $37^{\circ} \mathrm{C}$ at a rotation speed of $100 \mathrm{rpm} .10 \mathrm{ml}$ sample was withdrawn at $1 \mathrm{hr}$ interval and analyzed spectrophotometrically at $276 \mathrm{~nm}$ to determine the concentration of drug present in the dissolution medium. The initial volume of the dissolution fluid was maintained by adding 10 $\mathrm{ml}$ of fresh dissolution fluid after each withdrawal. The dissolution studies were repeated using pH 6.8 All experiments were conducted in triplicate. Results of Drug release study are shown in figure 5 and 6.

\section{RESULTS AND DISCUSSION}

Preparation and optimization of Acrycoat S100 microspheres of Glipizide

Formulation B1 was found good with Morphology, Yield and Drug Entrapment.

Table 3: Evaluation parameters of microspheres of Glipizide batches B1 to B3

\begin{tabular}{|c|c|c|c|c|}
\hline Batches & $\begin{array}{c}\text { Mean particle size } \\
(\boldsymbol{\mu m})\end{array}$ & \% Yield & \% Floating & $\begin{array}{c}\text { Incorporation } \\
\text { Efficiency }\end{array}$ \\
\hline B1 & $330 \pm 35$ & $89 \%$ & $48 \%$ & $76 \%$ \\
\hline B2 & $420 \pm 45$ & $87 \%$ & $87 \%$ & $94 \%$ \\
\hline B3 & $370 \pm 45$ & $84 \%$ & $56 \%$ & $89 \%$ \\
\hline
\end{tabular}

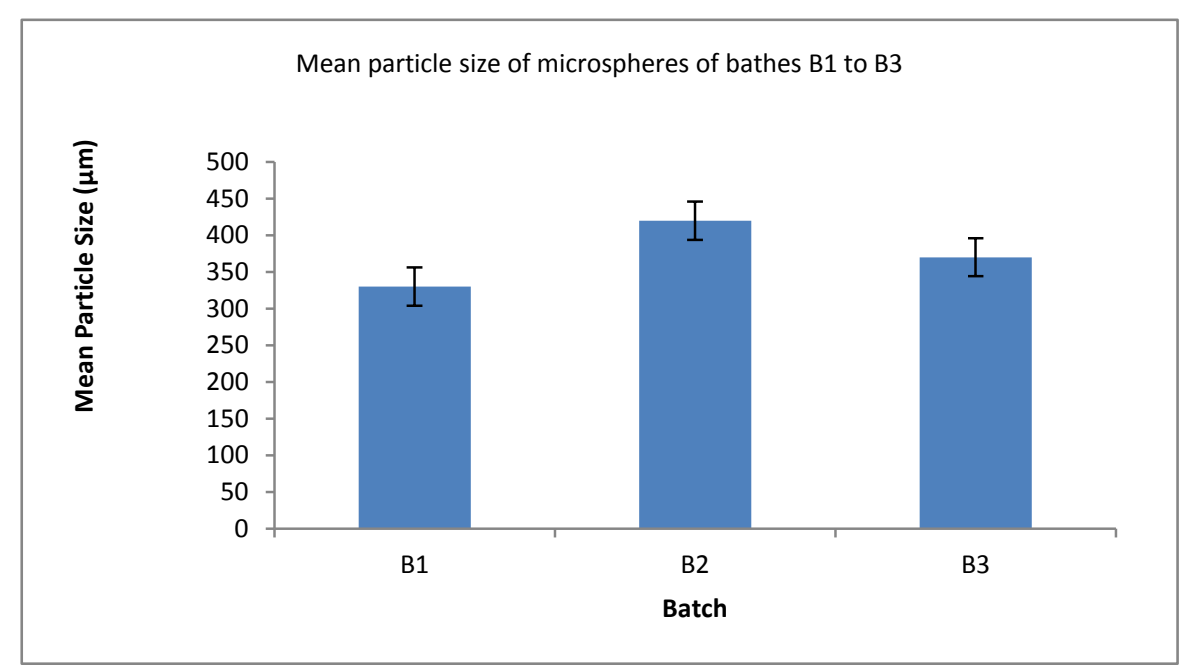

Figure 1: Mean particle size of microspheres of bathes B1 to B3

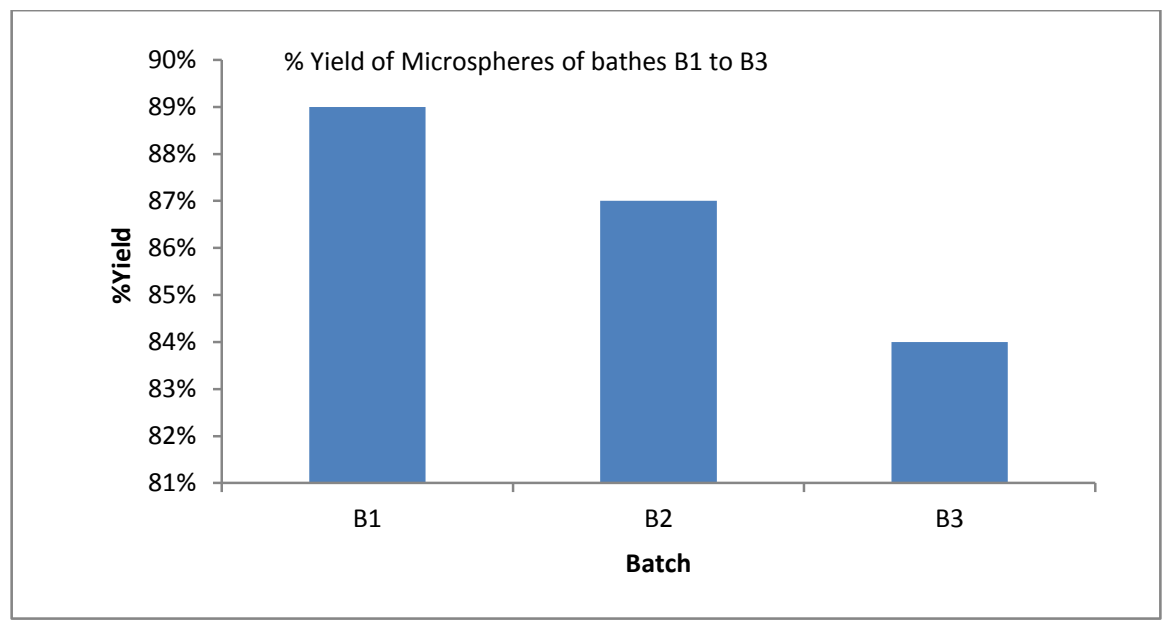

Figure 2: \% Yield of Microspheres of bathes B1 to B3 


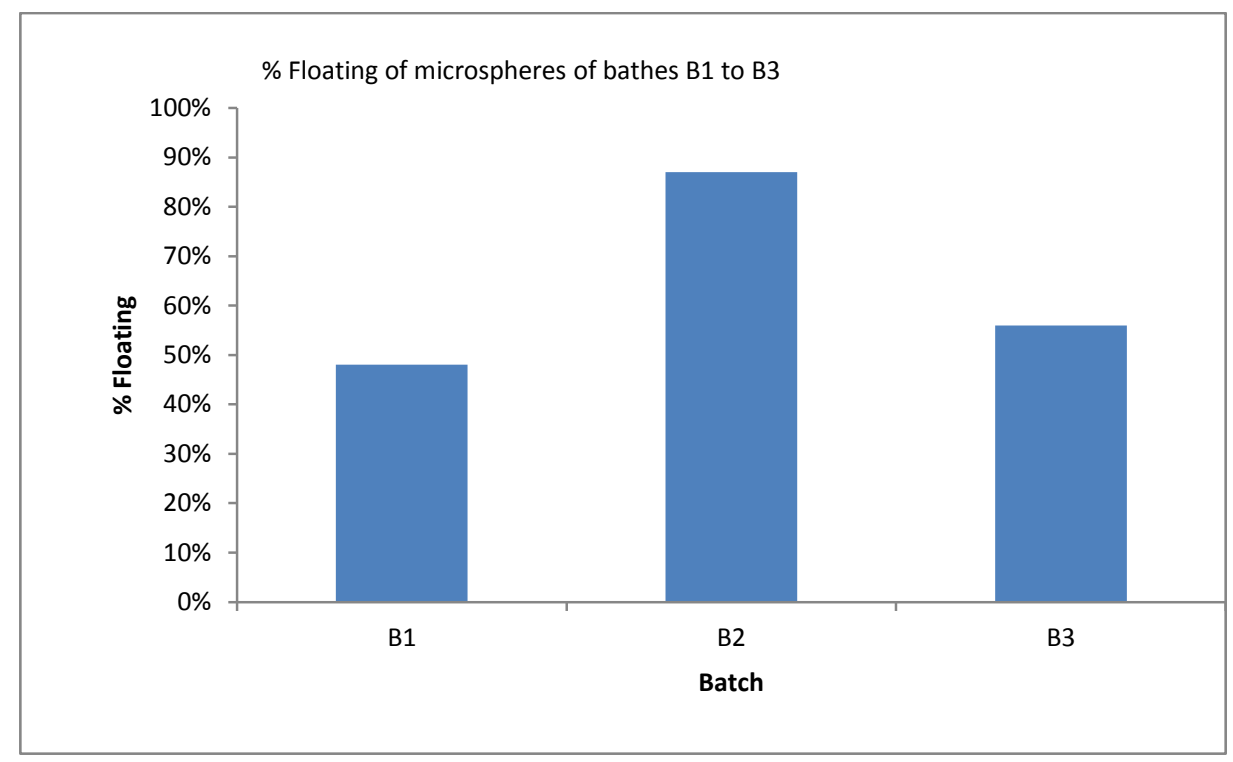

Figure 3: \% Floating of microspheres of bathes B1 to B3

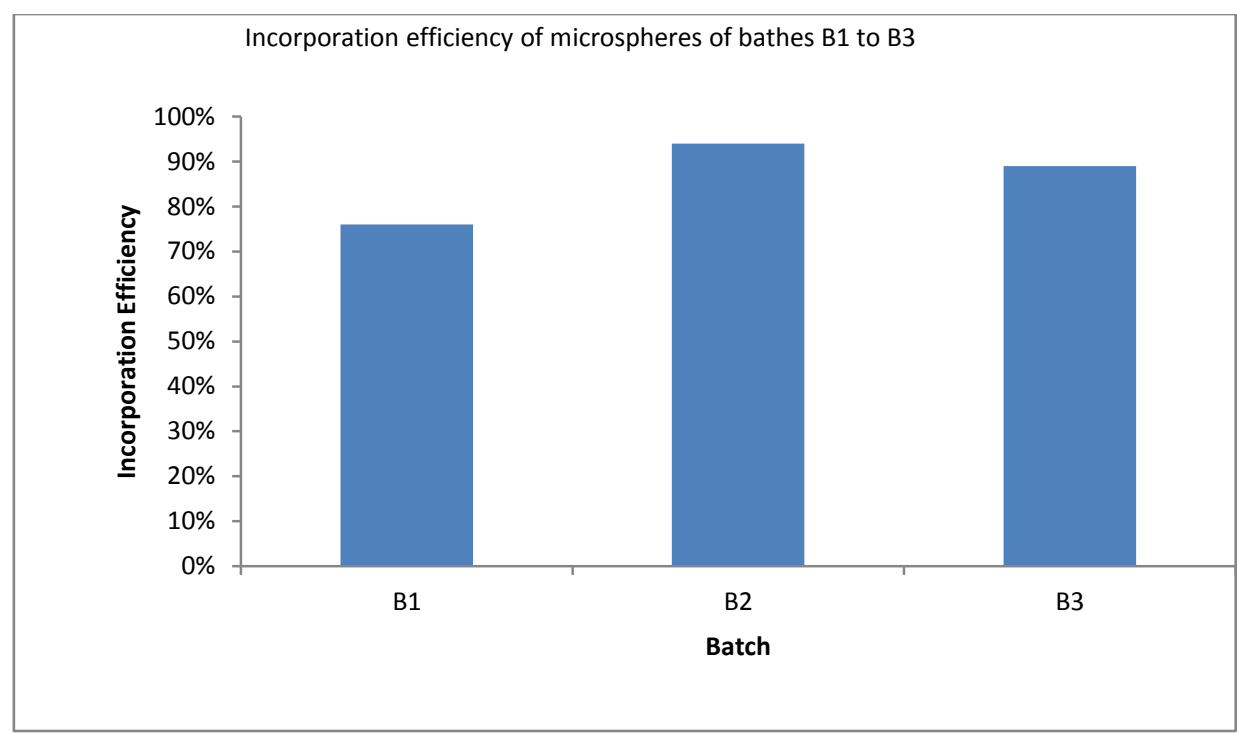

Figure 4: Incorporation efficiency of microspheres of bathes B1 to B3

In Formulation B2, Glyceryl Monostearate was replaced with Acryflow. Acryflow is Hydrogenated Castor Oil, which is having low density and it helps the microspheres to float. Formulation B3 was evaluated for Mean particle size $(\mu \mathrm{m}), \%$ Yield $\%$, Floating and Incorporation Efficiency as shown in Table 3. It is comparable to Formulation B1 with respect to all parameters except \% floating. Floating is reasonably good in Formulation B2 as compared to Formulation B1.

In dissolution study, due to their floating nature, the microspheres were forcibly immersed into the dissolution media to avoid adherence to the surface of the dissolution jar, thus leading to nonparticipation in the dissolution process. The drug release was extended to more than $12 \mathrm{hr}$.
From Table 4 it can be seen that drug release rate of the formulation $\mathrm{B} 2$ is much less as compared to formulation B1. . As a result there is some improvement in drug release and floating was also satisfactory. So we further decreased the amount of Glyceryl Monostearate and acryflow in formulation B3 but there is no significant increase in dissolution profile while $\%$ floating was decreased. So in further experiment, we have to use at least $0.25 \mathrm{mg}$ of Glyceryl Monostearate or acryflow.

Thus, in order to enhance the drug release rate from the microspheres, they were prepared by mixing hydrophilic or hydrophobic polymer in Acrycoat S100. (Batches B4 to B7) 
The microspheres prepared upon mixing Acrycoat L100 in Acrycoat S100 (batches B4) was having rough surface. The amount of Glipizide released from microspheres prepared by mixing Acrycoat L100 was high, probably due to facilitated penetration of dissolution media in the microspheres. Increased amount of Acrycoat L100 (0.2 gm) was used in formulation B5 for further improvement of dissolution rate but it didn't improve dissolution rate significantly.

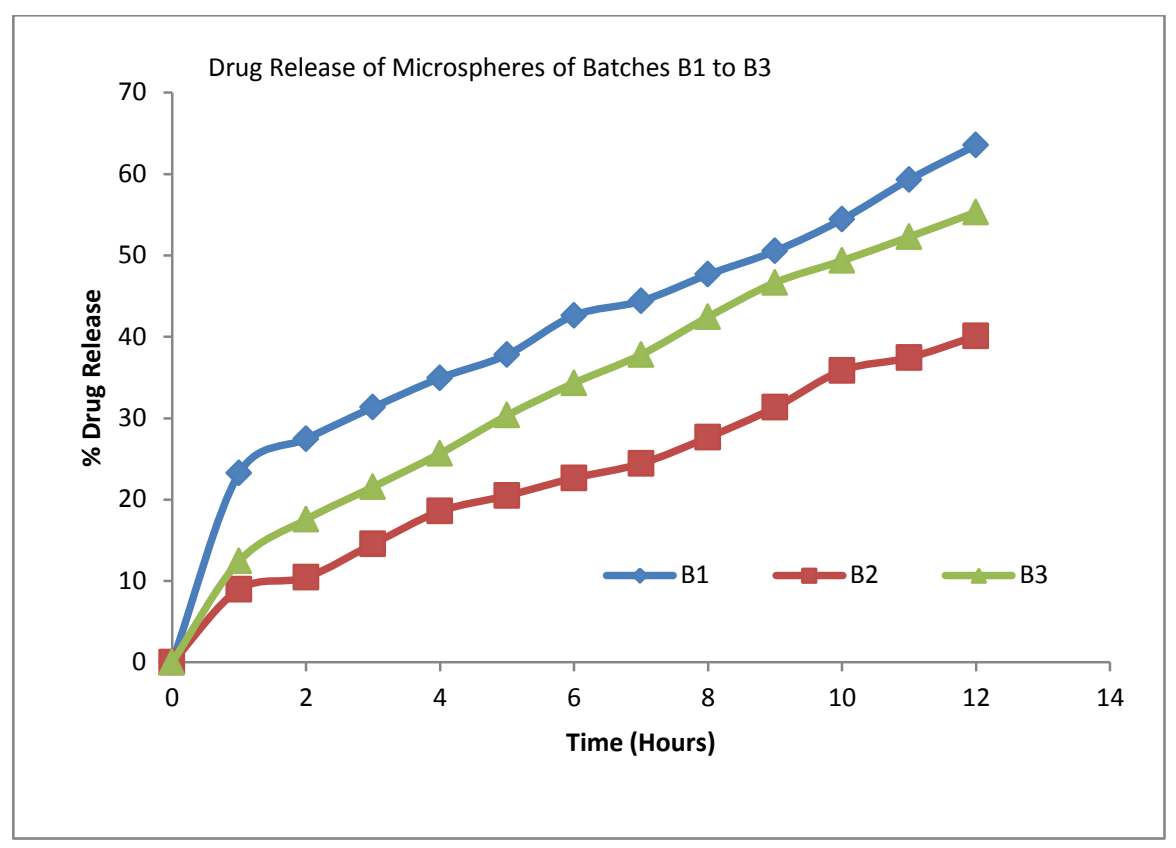

Figure 5: \% Drug Release of Microspheres of Batches B1 to B3

Table 4: Evaluation of microspheres of batches B4 to B7

\begin{tabular}{|c|c|c|c|c|}
\hline Batches & \%Yield & $\begin{array}{c}\text { Incorporation } \\
\text { Efficiency }\end{array}$ & \% Floating & $\begin{array}{c}\text { Mean particle size } \\
(\boldsymbol{\mu m})\end{array}$ \\
\hline B4 & $89 \%$ & $92 \%$ & $71 \%$ & $390 \pm 54$ \\
\hline B5 & $87 \%$ & $78 \%$ & $80 \%$ & $480 \pm 32$ \\
\hline B6 & $92 \%$ & $91 \%$ & $77 \%$ & $310 \pm 20$ \\
\hline B7 & $90 \%$ & $84 \%$ & $73 \%$ & $325 \pm 30$ \\
\hline
\end{tabular}

In the case of hydroxypropyl methyl cellulose (HPMC) batches B6, buoyancy was high. HPMC was considerably soluble and gelled in dissolution media. Additionally, microspheres are having smooth surfaces. Thus, buoyancy appeared to be high due to the difficulty in penetration of dissolution media through the rigid smooth surfaces.

It has been shown that presence of HPMC improves the solubility of Glipizide in the formulation. This was based on the assumption that polymer dissolution during the time course of study changes the surface tension of the medium and increases drug solubility. This can be attributed to the surface activity of the polymer. The surface tension of water $\left(\right.$ at $20^{\circ} \mathrm{C}$ ) is $\sim 72 \mathrm{mN} / \mathrm{m}$ and that of HPMC polymer at the same temperature ranges from 42 to $64 \mathrm{mN} / \mathrm{m}$. This reduction in surface tension can increase the wetting of the drug particles and as a result, increase the solubility ${ }^{3}$.

It was found that the drug release rate and buoyancy of microspheres prepared by co formulating HPMC was relatively improved due to gelation in dissolution media. Therefore, the effect of HPMC mixing ratio on physicochemical properties and drug releasing behaviors of the microspheres were investigated as shown in Table 4. Although the recovery of microspheres appeared unchanged by HPMC 
ratio, the buoyancy decreased with increasing HPMC ratio. These results were attributable to the conversion of spherical microspheres to needle-like particles possessing no hollow structure. In addition, the dissolution media can readily penetrate into microspheres the increased dissolution of HPMC in the solution. The amount of Glipizide released from microspheres in $0.1 \mathrm{~N} \mathrm{HCl}$ containing $0.02 \%$ Tween 20 (pH 1.2) increased with increasing HPMC ratio. This behavior was explained by the increased contact area of particles with the medium due to the poor buoyancy associated with increased HPMC ratio. The amount of Glipizide released from microspheres in dissolution media significantly increased in association with increased HPMC ratio. In conclusion, a recommendable preparation formulation of microspheres to increase the bioavailability of Glipizide is formulation B6 due to their desired drug release and floatable properties. Formulation B7 containing $0.25 \mathrm{gm}$ acryflow still need improvement in drug release. So quantity of HPMC was increased to $0.2 \mathrm{gm}$. Similarity values between drug release profile of formulation B6 to that of theoretical profile IS 86.509 .

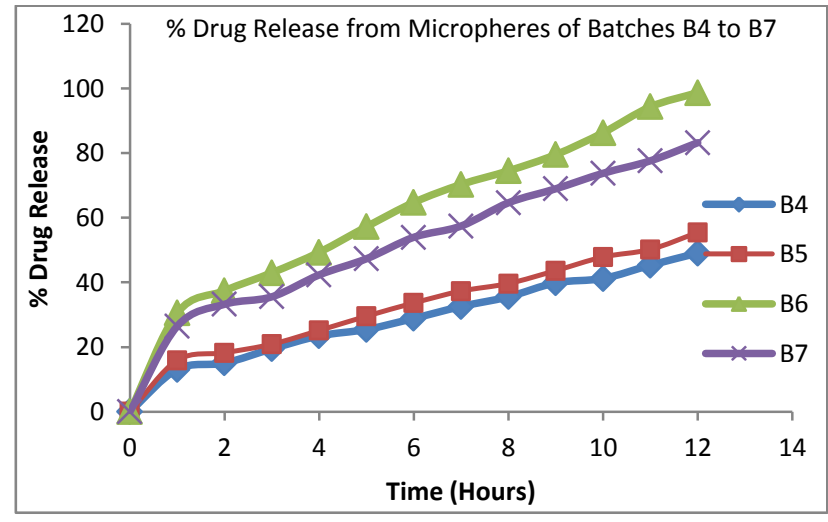

Figure 6: \% Drug Release from Micropheres of Batches B4 to B7

\section{CONCLUSION}

Present work involves attempts to improve floating time of glipizide by formulation of hollow microspheres incorporating Glyceryl Monostearate and acry flow. The floating microspheres were evaluated for percentage yield, drug loading, in-vitro buoyancy behavior as well as in-vitro drug release. The micrometric properties were found to be good and scanning electron microscopy shows that the microspheres were spherical with smooth surface and a hallow cavity inside microspheres. The practical yield was found to be in the range of 83.88-90.98\% and with a particle size range of $320-480 \mu \mathrm{m}$. The percent entrapment is about $76 \%$ to $91 \%$ which decreased with increase in HPMC concentration in the formulations. The microspheres with high concentrations of Acrycoat S100 showed higher buoyancy. The in-vitro release was slow and extended to more than 12 hours which increased with significant increase in HPMC concentration but decreased in buoyancy character. Release obeys zero order kinetics and the drug release was diffusion controlled. Hence it can be concluded that the floating microsphere of Glipizide may prolong drug release thereby improving bioavailability and enhance opportunity of absorption in stomach.

\section{ACKNOWLEDGEMENTS}

The authors are thankful to IJDRA journal for publishing our article.

\section{CONFILCTS OF INTEREST}

The authors declare that there are no conflicts of interest.

\section{REFERENCES}

1. Wikipedia. Glipizide [Internet]. 2017 [cited 2017 Nov 16]. Available from:

www.wikipedia.com,

2. Glipizide extended release. Newyork NY 10017: Pfizer, Inc; 2007 May.

3. Mustafa Sinan Kaynak H, Suheyla Kas, Levent Oner. "Formulation off Controlled release Glipizide Pellets using Pan Coating Method" Hacetlepe University. Journal of the Faculty of Pharmacy. 2007; 27(2):93106.

4. El-Kamal AH, Sokar MS, Al-Gamal SS, Naggar VF. "Preparation \& Evaluation of Ketoprofen floating oral delivery system". Int. J. Pharm. 2001; 220:13-21.

5. Gavini V, Murthy MS, Rao SK, Kumar KP. Formulation and invitro evaluation of buoyant drug delivery system of glipizide using acrylic polymer. Journal of Drug Delivery and Therapeutics. 2014; 4(6):107-13. doi:10.22270/jddt.v4i6.985

6. Patel A, Ray S, Thakur RS. "Invitro evaluation and optimization of controlled release floating drug delivery system of Metformin hydrochloride". 2006; 14:57-64.

7. Agrawal D, Ranawat MS., Chauhan CS., Kamble R. Formulation and charecterisation of colon targeted ph dependent microspheres of capecitabine for colorectal cancer. Journal of Drug Delivery \& Therapeutics. 2013; 3(6):215-22. doi:10.22270/jddt.v3i6.747. 
8. Lachman L, Lieberman HA, Kanig J. Theory and Practice of Industrial Pharmacy, II Edn. Bombay: Varghese Publisher; 1976. p 52-57.

9. Singh B, Kanoujia J, Pandey M, Saraf S. "Formulation and Evaluation of Floating Microspheres of Famotidine". Int $\mathrm{J}$ of PharmTech Research. 2010; 2(2):1415-20.

10. Patel A, Ray S, Thakur RM. In vitro evaluation and optimization of controlled release floating drug delivery system of metformin hydrochloride. 2006; 14(2):57-64.

11. Singh S, Koland M. Formulation and evaluation of pulsatile drug delivery systems of glipizide for the management of type-ii diabetes mellitus. Journal of Drug Delivery \& Therapeutics. 2016; 6(1):11-18. doi:10.22270/jddt.v6i1.1192 